\title{
O conhecimento sobre hepatites B e C dos Estudantes de uma Escola Particular do Município de Vitória da Conquista - BA
}

\author{
Ana Karla Pires Santos ${ }^{\prime}$; David Jesus de Almeida ${ }^{2}$; Ioneide Silva Santos ${ }^{3}$; Laricy Silva dos Santos ${ }^{4}$; \\ Luana Maria de Souza Varges $^{5}$; Nivaneide Ferreira Ramos de Sousa Lacerda ${ }^{6}$; Yara Neves dos Santos ${ }^{7}$
}

\begin{abstract}
Resumo: As hepatites virais B e C são doenças infecciosas que impactam asaúde pública no mundo, podendo acometer qualquer indivíduo. As mesmas são consideradas doenças silenciosas e assintomáticas, na maioria das vezesapresentando perda de qualidade de vida dos pacientes e comunicantes, correndo risco dessas doenças evoluírem, gerando gastos para o sistema único de saúde. Oobjetivo geral desta pesquisa inclui em verificar o conhecimento de estudantes do ensino médio de uma escola particular no município de Vitória da Conquista BA, sobre hepatite B e C. Como metodologia abordada, trata-se de uma pesquisa descritiva, exploratória de natureza quantitativa, desenvolvida em uma instituição de ensino privado do município de Vitória da Conquista - BA, com os estudantes 83 estudantes do $1^{\circ}$ ao $3^{\circ}$ ano do Ensino Médio. Desta maneira, destacando-se que 70 (84\%) refere à coloração amarelada da pele e do fundo dos olhos como sintoma predominante da doença, perda de peso $49(59 \%)$ e urina escura 28 (34\%). Assim, os resultados evidenciam déficit no conhecimento dos alunos sobre o tema. Sendo necessário ampliaro conhecimento dessas patologias na rede de ensino.
\end{abstract}

Palavras-Chave: Hepatites B e C, Ação de Estágio, Conhecimento.

\section{The Knowledge about $B$ and C Hepatitis of Students of a Private School in Vitória da Conquista, Bahia}

\begin{abstract}
Viral hepatitis B and C are infectious diseases that impact public health in the world, and can affect any individual. These are considered silent and asymptomatic diseases, most of them presenting loss of quality of life of the patients and communicants, at the risk of these diseases evolving, generating expenses for the single health system. The general objective of this research is to verify the knowledge of high school students of a private school in the city of Vitória da Conquista - BA, on hepatitis B and C. As methodology, it is a descriptive, exploratory research of a quantitative nature, Developed in a private educational institution of the municipality of Vitória da Conquista - BA, with the students 83 students from the 1st to the 3rd year of High School. Thus, 70 (84\%) referred to the yellowing of the skin and the fundus of the eyes as a predominant symptom of the disease, weight loss $49(59 \%)$ and dark urine $28(34 \%)$. Thus, the results show a deficit in students' knowledge about the subject. It is necessary to increase knowledge of these pathologies in the educational network.
\end{abstract}

Keywords: Hepatitis B and C, Stage for Action, Knowledge.

\footnotetext{
${ }^{1}$ Graduação em Enfermagem pela Faculdade de Tecnologia e Ciências e Especialização em Saúde Coletiva com Ênfase em PSF. Docente permanente na Faculdade Independente do Nordeste - Fainor. Autor correspondente: anakarla@ fainor.com.br;

${ }^{2}$ Graduação em Enfermagem pela Faculdade Independente do Nordeste, Brasil;

${ }^{3}$ Graduanda em enfermagem pela Faculdade Independente do Nordeste. Graduada em Pedagogia pela Universidade Estadual do Sudoeste da Bahia;

${ }^{4}$ Faculdade Independente do Nordeste, Brasil;

${ }^{5}$ Faculdade Independente do Nordeste, Brasil;

${ }^{6}$ Graduanda do curso de Enfermagem pela Faculdade Independente do Nordeste. Professora na Rede Municipal de Ensino do Município de Cândido Sales;

${ }^{7}$ Faculdade Independente do Nordeste, Brasil.
} 


\section{Introdução}

As hepatites virais são doenças causadas por diferentes agentes etiológicos de distribuição universal. Possuem semelhanças do ponto de vista clínico-laboratorial, mas apresentam importantes diferenças epidemiológicas quanto à sua evolução (FEITOSA, 2015).

São infecções causadas por vírus e sua fisiopatologia está baseada na resposta inflamatória ao fígado. As hepatites apresentam uma alta incidência no Brasil, sendo entendida como doença de notificação compulsória. Entre os anos de 2013 e 2014, foram notificados 17.814 e 17.940 casos de hepatite B no Brasil e destes, 17 mil casos são confirmados a cada ano (Brasil, 2015).

Em Vitória da Conquista o tratamento das hepatites B e C são realizados pelo Centro de Apoio e Atenção a Vida(CAAV) e para hepatite A, nas unidades de saúde. Segundo dados coletados em 2014, foram notificados 105 casos positivos da doença em Vitória da Conquista e em 2015, até o mês de julho, 60 casos (PMVC, 2014).

As doenças inflamatórias do fígado dominam a prática clínica da hepatologia. Isto é, qualquer insulto ao fígado pode matar hepatócitos e recrutar células inflamatórias, as quais são frequentes condições crônicas em longo prazo, que devem ser tratadas clinicamente. Por isso, entre as doenças inflamatórias, a infecção é de longe a mais frequente (BALTERet al., 2014).

O fígado é envolvido na maioria das vezes nas infecções transportadas pelo sangue, quer sistêmica, quer originada dentro do abdome. As infecções virais sistêmicas que podem comprometer o fígado incluem: a mononucleose infecciosa; citomegalovírus; e a febre amarela (BRASIL, 2010).

A hepatite B Viral (HBV) pode produzir hepatite aguda com resolução; hepatite crônica, evoluindo para cirrose; hepatite fulminante com necrose maciça do fígado; a qual é pano de fundo para infecção pelo vírus da hepatite D. Os pacientes com hepatite crônica são portadores de vírus em replicação ativa tornando- se uma fonte de infecção para outros indivíduos (FOCACCIA; SCHUNCK, 2010). 
De acordo FERREIRA et al., (2014), a HBV é causa significativa aguda e crônica ao redor do mundo e pode ser transmitido percutaneamente (p. ex., uso de drogas intravenosas ou transfusão sanguínea), perinatalmente, e sexualmente.

Segundo dados da organização mundial da saúde (OMS), acontecem cerca de 600 mil mortes relacionadas à hepatite $\mathrm{B}$, por ano, em todo mundo. Atualmente, existem no mundo cerca de 350 milhões de portadores crônicos da infecção (FERREIRA; FAGUNDES e colaboradores, 2014).

Os vírus da Hepatite C foram descobertos em 1989 e são transmitidos como os vírus da hepatite B. A doença geralmente é assintomática, mas alguns indivíduos podem desenvolver icterícia, dores de cabeça, garganta, vômitos e fadiga. O maior perigo é a doença evoluir para cirrose hepática, além do risco de câncer de fígado (VILHENA; REIS, 2011).

Para MENEGOl (2013), o vírus da hepatite C (HCV) é uma causa importante de doença do fígado em todo mundo. Estima-se que 40mil novas infecções de HCV ocorram anualmente, nos Estados Unidos, aproximadamente 3,9 milhões de americanos tem anticorpos contra o HCV, 70 \% desses indivíduos têm evidência de infecção crônica conforme determinado pela presença de DNA viral no soro.

O interesse em realizar este estudo se deu após observar a falta de conhecimento entre as pessoas sobre as hepatites virais. Este trabalho visa fomentar e esclarecer acerca das hepatites B e C, nas escolas, sendo que a patologia se tornou um grave problema de saúde pública no Brasil e no mundo. Pensando no pilar saúde e educação e nas práticas de promoção e prevenção de agravos à saúde, busca - se fortalecer a parceria entre profissionais da enfermagem e a escola. A articulação entre a escola e unidade de saúde é, portanto, uma demanda do programa saúde na escola, de acordo as diretrizes do programa saúde e prevenção na escola.

Diante do exposto, este estudo teve como objetivo verificar o conhecimento de estudantes do ensino médio de uma escola particular no município de Vitória da Conquista BA, sobre hepatite B e C. 


\section{Metodologia}

Trata-se de uma pesquisa descritiva, exploratória de natureza quantitativa, desenvolvida em uma instituição de ensino privado do município de Vitória da Conquista BA, com os estudantes do $1^{\circ}$ ao $3^{\circ}$ ano do Ensino Médio.

São matriculados no ensino médio da escola 110 estudantes, destes, 83 estavam presentes no dia da coleta e aceitaram participar do estudo de forma voluntária.

A técnica utilizada para realização da coleta dos dados foi à aplicação de doisquestionários: o primeiro correspondeu a características individuais, nas quais foram investigados os aspectos sociodemográficos e econômicos (condição de moradia, número de pessoas no domicílio, meio de transporte utilizado, renda familiar etc.); o segundo um questionário contendo oito questões objetivas, referentes ao conhecimento sobre as hepatites virais B e C.

Antes da aplicação os alunos foram instruídos quanto ao tema e propósito do estudo. Foi aplicado o Termo de Consentimento Livre e Esclarecido (TCLE) contendo também informações do projeto para que os responsáveis legais assinassem autorizando-os a participar do estudo. Só após recolhermos o TCLE foram aplicados os questionários. Após aplicação do mesmo, foi apresentado um vídeo de oito minutos, com informações pertinentes das hepatites virais, com intuito de possibilitar o conhecimento da temática.

Após a coleta, os dados foram compilados e posteriormente submetidos à análise mediante estatística descritiva. Os dados coletados foram registrados em tabelas elaboradas no programa Excel.

O projeto foi aprovado pelo Comitê de Ética em Pesquisa da Faculdade Independente do Nordeste - FAINOR, sob parecer de aprovação2.056.169.

O projeto O CONHECIMENTO SOBRE HEPATITES B e C DOS ESTUDANTES DE UMA ESCOLA PARTICULAR DO MUNICIPIO DE VITÓRIA DA CONQUISTA BA com o número CAAE 67943917.6.0000.5578, tem data de inicio prevista para 24/04/2017. 


\section{Resultados e Discussão}

Diante os resultados, encontram-se matriculados no ensino médio da escola 110 estudantes, destes, 83 estavam presentes no dia da coleta e aceitaram participar do estudo de forma voluntária.

Tabela 1- Distribuição percentual em relação a moradia, quantidade de pessoas que moram na casa, frequência local ao ensino médio e realização do ensino (local).

\begin{tabular}{|c|c|c|c|}
\hline MORADIA & Respostas & $\mathbf{N}$ & $\%$ \\
\hline Casa ou apartamentos próprio com & & 54 & 77 \\
\hline $\begin{array}{l}\text { a família } \\
\text { Em casa ou apartamento próprio } \\
\text { sozinho (a) }\end{array}$ & & 6 & 9 \\
\hline Em quarto ou cômodo alugado & & 3 & 4 \\
\hline Em habitação coletiva & & 0 & 0 \\
\hline Outras situações & & 7 & 10 \\
\hline \multicolumn{4}{|l|}{$\begin{array}{l}\text { QUANTIDADE DE PESSOAS QUE } \\
\text { MORAM NA CASA }\end{array}$} \\
\hline De 1 a 3 pessoas & & 29 & 40 \\
\hline De 1 a 5 pessoas & & 40 & $55,5 \%$ \\
\hline De 1 a 7 pessoas & & 3 & $4,5 \%$ \\
\hline \multicolumn{4}{|l|}{$\begin{array}{c}\text { ONDE FREQUENTOU O ENSINO } \\
\text { MÉDIO }\end{array}$} \\
\hline Todo em escola pública & & 4 & 5,4 \\
\hline Todo em escola particular com bolsa & & 3 & 4,1 \\
\hline Maior parte em escola particular & & 11 & 15,1 \\
\hline Maior parte em escola pública & & 2 & 2,7 \\
\hline $\begin{array}{l}\text { Maior parte em escola particular } \\
\text { com bolsa }\end{array}$ & & 1 & 1,4 \\
\hline Todo em escola particular & & 52 & 71,2 \\
\hline Todo em escola pública & & 4 & 5,4 \\
\hline FAZ O ENSINO MÉDIO & & & \\
\hline $\begin{array}{l}\text { Particular integral - } 52 \text { que equivale } \\
\text { a } 68,4 \%\end{array}$ & & 52 & 68,4 \\
\hline $\begin{array}{l}\text { Bolsa parcial - } 20 \text { que equivale a } \\
26,3 \%\end{array}$ & & 20 & 26,3 \\
\hline $\begin{array}{l}\text { Bolsa integral - } 4 \text { que equivale a } \\
5,3 \%\end{array}$ & & 4 & 5,3 \\
\hline
\end{tabular}


Neste contexto a tabela indica a Distribuição percentual em relação a moradia, quantidade de pessoas que moram na casa, frequência local ao ensino médio e realização do ensino (local), assim apresenta-se em relação a casa ou apartamentos próprio com a família 77\%, 55,5\% dos participantes de moram de 5 pessoas, 71,2\% frequenta escola particular com 68,4 faz o ensino médio particular integral.

Tabela 2- Distribuição percentual em relação a utilização do meio de transporte e renda mensal.

\section{MEIO DE TRANSPORTE QUE}

UTILIZA

\begin{tabular}{|lcc|}
\hline A pé, carona, bicicleta & 32 & 38 \\
\hline Transporte coletivo & 9 & 10,7 \\
\hline Transporte escolar & 10 & 11,9 \\
\hline Transporte próprio & 33 & 39,2 \\
\hline A pé, carona, bicicleta & 32 & 38 \\
\hline Transporte coletivo & 9 & 10,7 \\
\hline Transporte escolar & 10 & 11,9 \\
\hline
\end{tabular}

RENDA MENSAL

\begin{tabular}{|lcc|}
\hline Nenhuma & 9 & 11,5 \\
\hline De 1 a 3 salários mínimos & 13 & 16,6 \\
\hline Até 5 salários mínimos & 8 & 10,2 \\
\hline De 5 a oito salários mínimos & 19 & 24,3 \\
\hline Superior a 8 salários mínimos & 27 & 34,6 \\
\hline Benefício sociogovernamental & 2 & 2,2 \\
\hline De 1 a 3 salários mínimos & 13 & 16,6 \\
\hline Até 5 salários mínimos & 8 & 10,2 \\
\hline
\end{tabular}

Assim, em relação aos resultados 39,2\% dos participantes utilizam transporte próprio, em relação a renda34,6\% dos participantes, possuem renda mensal superior de a 8 salários mínimos. 
Tabela 3- Distribuição das respostas segundo o conhecimento das hepatites virais B e C.

\begin{tabular}{cccc}
\hline & Respostas & N & \% \\
\hline Sabe o que é hepatite B & Sim & 34 & 41 \\
& Não & 49 & 59 \\
Sabe o que é hepatite C & Sim & 30 & 36 \\
& Não & 53 & 64 \\
Sabe qual órgão é acometido & Sim & 74 & 89 \\
\cline { 2 - 4 } & Não & 09 & 11 \\
\hline
\end{tabular}

Fonte: Aplicação de questionário em uma escola particular de Vitoria da Conquista, 2017

$\mathrm{Na}$ tabela 3 os resultados apresentados no estudo sugerem que a maioria dos adolescentes refere não conhecer o que é hepatite B 49 (59\%) assim como a hepatite C 53 (64\%). Isso infere que o conhecimento a respeito das hepatites virais é restrito entre os adolescentes e que a falta de esclarecimento sobre a doença implica em suscetibilidade e exposição ao vírus. Em comparação, o resultado em relação a qual órgão é acometido pelo vírus foi o oposto, 74 (89\%) dos adolescentes refere conhecer o órgão alvo para a ação do vírus e apenas $9(11 \%)$ relata ser outro órgão.

Tabela 4- Distribuição das respostas quanto ao conhecimento dos sinais e sintomas das hepatites virais $\mathrm{B}$ e $\mathrm{C}$.

\begin{tabular}{ccc}
\hline & N & \% \\
\hline Cansaço & 16 & 19 \\
Perda de peso & 49 & 59 \\
Dor muscular & 14 & 16 \\
Urina escura & 28 & 34 \\
Coloração amarelada da & 70 & 84 \\
pele e do fundo dos olhos & & \\
\hline
\end{tabular}

Fonte: Aplicação de questionário em uma escola particular de Vitoria da Conquista, 2017

A tabela 4 apresenta que o conhecimento dos alunos sobre os sinais e sintomas da doença foi relevante. Destacando-se que 70(84\%)refere à coloração amarelada da pele e do fundo dos olhos como sintoma predominante da doença, perda de peso 49(59\%) e urina escura 28(34\%). Mesmo sem informações sobre as hepatites virais foi elencado por eles um dos principais sinais e sintomas relacionado a patologia. 
Tabela 5- distribuição das respostas quanto ao conhecimento dos meios de transmissão das hepatites virais B e C.

\begin{tabular}{ccc}
\hline & N & \% \\
\hline Água & 24 & 29 \\
Comida & 07 & 8,4 \\
Sexual & 39 & 47 \\
Pelo ar & 08 & 9,6 \\
Contato pessoa & 08 & 9,6 \\
Contato com sangue & 51 & 61,4 \\
Suor, saliva, fezes, urina & 31 & 37,3 \\
\hline
\end{tabular}

Fonte: Aplicação de questionário em uma escola particular de Vitoria da Conquista, 2017

A tabela 5 relata que quanto ao conhecimento dos meios de transmissão da hepatite B e C, $51(61,4 \%)$ os participantes responderam que ocorre pelo contato com sangue. Assim, em segundo lugar prevaleceu com 39 (47\%) o contato por via sexual, e $31(37,3 \%)$ dos alunos opinaram sobre transmissão por suor, saliva, fezes e urina. Neste caso a maioria dos participantes respondeu de maneira adequada sendo que a transmissão das hepatites $\mathrm{B}$ e C realmente são por via sexual e contato sanguíneo. Aminoria dos participantes respondeuque outros tipos de contato não possuem nenhum vínculo de transmissão, talvez seja pela falta de conhecimento do processo patológico da doença.

Segundo FERREIRA et al., (2014), A infecção se dá pelo contato com sangue ou outras secreções corporais. Desta forma, a infecção pode ocorrer por relações sexuais, transfusão de sangue e/ou hemoderivados, uso de drogas injetáveis ilícitas, normalmente por seringas e agulhas compartilhadas, transmissão mãe-filho (durante a gestação e/ou na passagem pelo canal do parto e amamentação), por contato interpessoal prolongado e por acidentes com material perfuro cortante, cuja maior exposição é de profissionais da área de saúde.

Tabela 6 - Distribuição das respostas quanto ao conhecimento dos meios de prevenção das hepatites virais $\mathrm{B}$ e $\mathrm{C}$.

\begin{tabular}{ccc}
\hline & N & \% \\
\hline Evitar partilhar objetos pessoais & 37 & 44,5 \\
Usar preservativos nas relações sexuais & 49 & 59 \\
Não compartilhar agulhas ou seringas & 57 & 68,7 \\
$\begin{array}{c}\text { Usar agulhas descartáveis para } \\
\text { procedimentos invasivos }\end{array}$ & 38 & 45,8 \\
\hline
\end{tabular}

Fonte: Aplicação de questionário em uma escola particular de Vitoria da Conquista, 2017 
A tabela 6 mostra o conhecimento dos participantes em relação aos meios de prevenção da hepatite B e C, neste caso, $57(68,7 \%)$ responderam que a prevenção ocorre por não compartilhar agulhas ou seringas, 49 (59\%) dos participantes opinaram sobre o uso preservativos nas relações sexuais. É importante ressaltar que as demais respostas não fazem parte dos meios de prevenção, porém as devidas respostas se deram pelos participantes não conhecer o meio de transmissão da doença.

O principal meio de transmissão se dá pelo contato com sangue infectado,compartilhar objetos cortantes e perfurantes, utensílios usados para a preparação de substancias endovenosa, sendo importante frisar o uso adequado de preservativo nas relações sexuais (ISOLANI; MELO, 2011).

$\mathrm{Na}$ tabela 7 abaixo, a maioria dos adolescentes refere conhecer quais pessoas são mais suscetíveis ao vírus da hepatite $\mathrm{B}$ e $\mathrm{C}$, sendo essa questão sugestiva a mais de uma alternativa, a distribuição das respostas ocorreu da seguinte forma: Quem pratica sexo sem camisinha 42 (50,6\%); recém-nascido de mães portadoras de hepatite 40 (48,1\%); Receptores de órgãos de tecidos transplantados 36 (43,4\%); quem tem contato social ou familiar com material de uso pessoal 30 (36,1\%); Profissionais de saúde 19 (22,9\%).

Tabela 7- Distribuição das respostas quanto ao conhecimento das pessoas que podem adquirir o vírus das hepatites $\mathrm{B}$ e $\mathrm{C}$.

\begin{tabular}{|c|c|c|}
\hline & $\mathbf{N}$ & $\%$ \\
\hline Quem pratica sexo sem camisinha & 42 & 50,6 \\
\hline $\begin{array}{c}\text { Recém nascido de mães portadoras de } \\
\text { hepatite }\end{array}$ & 40 & 48,1 \\
\hline $\begin{array}{c}\text { Receptores de órgãos de tecidos } \\
\text { transplantados }\end{array}$ & 36 & 43,4 \\
\hline Profissionais de saúde & 19 & 22,9 \\
\hline $\begin{array}{l}\text { Quem tem contato social ou familiar com } \\
\text { material de uso pessoal. }\end{array}$ & 30 & 36,1 \\
\hline
\end{tabular}

Fonte: Aplicação de questionário em uma escola particular de Vitoria da Conquista, 2017

Para Brasil (2010) a rede de políticas do Sistema Único de Saúde disponibiliza meios de prevenção principalmente por mecanismo de vacinações gratuitamente, onde previne a 
transmissão por via vertical. Todas as pessoas têm direito ao mecanismo de vacinação sendo realizada 3 doses por via intramuscular.

\section{Considerações Finais}

A partir da realidade sobre o conhecimento adquirido das hepatites $\mathrm{B}$ e $\mathrm{C}$ foi observado que os alunos do ensino médio de uma escola privada do município de Vitória da Conquista, não obtêm conhecimento sobre as hepatites virais Be C.

A análise dos dados apresentou que mesmo sem conhecimento sobre a doença os alunos souberam identificar os principais sintomas como: coloração amarelada da pele, perda de peso e urina escura, assim como os meios de transmissão (contato com sangue e via sexual).

Vê-se aqui confirmado o objetivo do presente estudo uma vez que, para que se possa desenvolver medida no âmbito escolar torna-se indispensável à colaboração e participação da sociedade civil. Assim este estudo buscou fomentar e permitir o conhecimento dos alunos acerca das hepatites e da importância de parceria entre escola e saúde pública fazendo com que os estudantes possuam mais informações sobre hepatites virais $\mathrm{B}$ e $\mathrm{C}$ e seus agravantes.

Os resultados e discussões mostram que há algumas diversas nas informações principalmente quanto a transmissão, mostrando assim, que pode haver uma dificuldade na classificação patológica. Cabem aos professores, profissionais da saúde e gestores em geral aprofundar mais sobre a referida patologia, cobrando no sentido de leitura e conhecimentos voltados as literaturas oferecendo assim, atualizações para a pratica do cotidiano.

O perfil sociodemográfico e econômico dos estudantes apresentama necessidade de programar na escola privada ações relacionadas às hepatites B e C. Destaforma para o município são relevantes algumas decisões da saúde pública em contribuir para o planejamento, gestão e avaliação de intervenções para o controle e prevenção desse agravo a saúde da população estudantil. 


\section{Referências}

BALTER S;STARK JH; KENNEDY J; BORNSCHLEGEL K;KONTY K. Estimativa da prevalência da hepatite C em Nova York usando dados de vigilância. Epidemiol Infect . 2014 Feb; 142 (2): 262-269. Disponível em: https://www.ncbi.nlm.nih.gov/pubmed/23657093. Acesso: 19 mar 2017.

BRASIL, Ministério da Saúde. Hepatites Virais. Boletim Epidemiológico. Brasília, DF: Ministério da Saúde, 2010.2 Disponível em: www.aids.gov.br/sites/default/..._p_boletim_hepatites_final_web_pdf_p_16377.pdf. Acesso 18 abr 2017.

Ministério da Saúde. Ministério lança campanha contra hepatites virais. Brasília, DF: Ministério da Saúde, 2015. Disponível em: http://www.brasil.gov.br/saude/2015/07/ministeriolancacampanhascontrahepatitesvirais. Acesso: 18 abr 2017.

FEITOSA, Taissa Viana; Nascimento, Sara Silva; Soares, Daianny Batista; Bomjardim, Gildeane Fonseca de Lima; Novaes Barbara Conceição Braga. HEPATITES VIRAIS: Uma análise dos fatores que determinam a proliferação do vírus. Disponível em: http://www.webartigos.com/artigos/hepatites-viraisuma-analise-dos-fatores-que-determinam-a-proliferacao-do-virus/129852. Acesso 18 abr 2017.

FERREIRA, ALEXANDRE RODRIGUES; FAGUNDES, ELEONORA DRUVE TAVARES ; QUEIROZ, THAIS COSTA NASCENTE; PIMENTA, JULIO ROCHA; JÚNIOR, RUBENS CARDOSO DO NASCIMENTO. Hepatites Virais A, B e C em crianças e adolescentes. RMMG Revista Médica de Minas Gerais Volume: 24.(Suppl.2) 2014. Disponível em: http://rmmg.org/artigo/detalhes/623. Acesso: 18 abr 2017.

FOCACCIA, R.; SCHUNCK, A. C. Levantamento da hepatite B e infecção C controle: procedimentos em instalações de manicure e pedicure em São Paulo. Jornal Brasileiro de Doenças Infecciosas, Salvador, v. 14, n. 5, p.502-507, set./out. 2010

GERHARD, Tatiana Engel ; SILVEIRA, Denise Tolfo. Métodos de pesquisa / coordenado pela Universidade Aberta do Brasil - UAB/UFRGS e pelo Curso de Graduação Tecnológica - Planejamento e Gestão para o Desenvolvimento Rural da

SEAD/UFRGS. - Porto Alegre: Editora da UFRGS, 2009. Disponível em: www.ufrgs.br/cursopgdr/downloadsSerie/derad005.pdf. Acesso: 17 abr 2017.

GIL, A. C. Como Elaborar Projetos de Pesquisa - 5. ed. - São Paulo, Atlas, 2009.

GOMES, MARCOS ANTÓNIO; PRIOLLI, DENISE GONÇALVES; TRALHAO, JOSÉ GUILHERME BOTELHO, MARIA FILOMENA. Carcinoma hepatocelular: epidemiologia, biologia, diagnóstico e terapias. Rev. Assoc. Med. Bras. vol.59 no.5 São Paulo Sept./Oct. 2013. Disponível em: http://www.scielo.br/scielo.php?script=sci_arttext\&pid=S010442302013000500017. Acesso 18 abr 2017.

MACEDO,Ticiana Fernandes de Sousa; SILVA, Nayandra Souza; SILVA, Vanessa Yuri Nakaoka Elias; KASHIWABARA, Tatiliana Geralda Bacelar. Hepatites virais - uma revisão de literatura. Braz. J. Surg. Clin. Res. V.5, n.1., pp.55-58 (Dez 2013 - Fev. Disponível em: http://www.mastereditora.com.br/periodico/20140429_213345.pdf. Acesso: 18 abr 2017

MENEGOL, Débora and SPILKI, Fernando Rosado. SeroprevalenceofHepatitis B and C markersatthepopulationlevel in themunicipalityof Caxias do Sul, southernBrazil. Braz. J. Microbiol. [online]. 2013, vol.44, n.4 [cited 2017-05-21], pp.1237-1240. Availablefrom: $<$ http://www.scielo.br/scielo.php?script=sci_arttext\&pid=S151783822013000400030\&lng=en\&nrm=iso $>$. 
Epub Feb 25, 2014. ISSN 1517-8382. http://dx.doi.org/10.1590/S1517-83822014005000013. Acesso: 14 abr 2017.

MORAIS, MARIA TEREZA MAGALHÃES; OLIVEIRA, THUANE DE JESUS. Perfil epidemiológico e sóciodemográfico de portadores de hepatite c de um município do sudoeste baiano. Rev. Saúde. Com 2015; 11(2):137-146. Disponível em: http://www.uesb.br/revista/rsc/v11/v11n2a04.pdf. Acesso: 05 abr 2017.

OLIVEIRA, MAXWELL FERREIRA DE. Metodologia científica: um manual para a realização de pesquisas em Administração / Maxwell Ferreira de Oliveira. -- Catalão: UFG, 2011. 72 p.: il.Disponível em: https://adm.catalao.ufg.br/up/567/o/Manual de metodologia cientifica__Prof Maxwell.pdf. Acesso: 17 abr 2017

Secretaria de Atenção à Saúde. Programa Nacional para a Prevenção e o Controle das Hepatites Virais. Manual de Aconselhamento em Hepatites Virais. Brasília, DF: Ministério da Saúde, 2005.

Secretaria de Atenção à Saúde. Departamento de Atenção Básica. HIV/Aids, hepatites e outras DST/ Ministério da Saúde, Secretaria de Atenção à Saúde, Departamento de Atenção Básica. - Brasília: Ministério da Saúde, 2006. 196p. il. - (Caderno de Atenção Básica, n. 18) (Série A. Normas e Manuais Técnicos).

Secretaria de Vigilância em Saúde. Departamento de Vigilância Epidemiológica. Hepatites virais: o Brasil está atento / Ministério da Saúde. Secretaria de Vigilância em Saúde. Departamento de Vigilância Epidemiológica. - 3. ed. - Brasília: Ministério da Saúde, 2008. 60p. - (Série B. Textos Básicos de Saúde).

SILVA; VITORINO et al,; Hepatites virais: B, C e D: atualização. RevBrasClin Med. São Paulo, 2012 mai-jun;10(3):206-18. Disponível em: http://files.bvs.br/upload/S/1679-1010/2012/v10n3/a2889.pdf. Acesso: 18 abr 2017.

VILHENA, M. R. P. H. C. O sujeito adolescente no cenário atual da hepatite C Algumas considerações. Revista oficial do Núcleo de Estudos da Saúde do Adolescente/UERJ. Vol.8 nº 4, 2011. Disponível em: http://www.adolescenciaesaude.com/detalhe_artigo.asp?id=298\#. Acesso em:18 de abr. 2017.

\section{Como citar este artigo (Formato ABNT):}

SANTOS, Ana Karla P.; ALMEIDA, David J.; SANTOS, Ioneide S.; SANTOS, Laricy S.; VARGES, Luana M. S.; LACERDA, Nivaneide F.R.S.; SANTOS, Yara N. O Conhecimento sobre Hepatites B e C, dos Estudantes de uma Escola Particular do Municipio de Vitória da Conquista - BA. Id on Line Revista Multidisciplinar e de Psicologia, Julho de 2017, vol.11, n.36, p.112-123. ISSN: 1981-1179.

Recebido: 03.06.2017

Aceito: 21.06 .2017 